\title{
Basalt reinforced concrete structures for retrofitting concrete surfaces
}

\author{
Benjamin Wolf ${ }^{1, *}$, Andrea Kustermann ${ }^{1}$, Christian Schuler $^{1}$ and Christoph Dauberschmidt ${ }^{1}$ \\ Ömer Bucak ${ }^{2}$ \\ ${ }^{1}$ University of Applies Sciences Munich, Faculty of Civil Engineering, Karlstraße 6, D-80333 Munich, Germany \\ ${ }^{2}$ Laboratory for steel and light metal construction University of Applies Sciences Munich, Karlstraße 6, D-80333 Munich, Germany
}

\begin{abstract}
Reinforced concrete facades exist since decades exposed to natural weather conditions. Thus nowadays lot of them are damaged by carbonation induced corrosion and therefor require repairing and retrofitting. The aim of this research project is to investigate the possibilities of basalt fibre reinforced concrete as repairing material and also basalt rebars as additional strengthening reinforcement. Investigations with basalt fibre reinforced mortar prisms showed best results in 3 point bending tests, tensile strength and also compressive strength using $0.3 \mathrm{Vol} .-\%$ basalt fibres in mixture. The mechanical properties of basalt rebars made of basalt fibre reinforced polymer were tested, showing higher values in tensile strength and Young's Modulus than comparable steel reinforcement samples. The basalt rebar reinforced concrete samples achieved higher ultimate loads in three-point bending test compared to SRC samples. But after failure in the bonding area no residual load capacity remained. Finally basalt reinforcement bars seems to be well suited for use as retrofitting material for facade elements, but numerous properties have to be examined in further investigations.
\end{abstract}

\section{BASALT REINFORCEMENT AS RETROFITTING MATERIAL}

Many concrete structures in Germany, built in the 50s and $60 \mathrm{~s}$, reinforced with traditional steel rebar, are constantly subjected by corrosion attack especially by carbonation. To avoid further corrosion damage after repairing the concrete surfaces alternative reinforcement materials have been investigated. There is a wide range of possible applications for use of basalt fibres due to its good thermal, electrical and sound insulating properties. In combination with its high specific strength and high resistance to aggressive media basalt fibres seems to be a good alternative as retrofitting material [1]. Due to its proven corrosion resistance under alkaline and nonalkaline conditions when compared to other glas materials [2] it should be possible to reduce the concrete cover of the retrofitting elements.

The basic idea of this research was to use basalt fibre reinforced polymer (BFRP) rebars as a strengthening material for use in concrete façade elements to be repaired. The mechanical properties of BFRP specimen were tested in reference to samples with traditional steel reinforcement (SRC). Additionally, the possibility of using an admixture of mortar reinforced with chopped basalt fibres for surface design is investigated. Generally "materials with fibrous structure are characterized by higher ratio of tensile strength and bending strength than the ultimate compressive strength" [3]. The use of fibres in the mortar can also significantly enhance the bond of strength between the existing material base and the repair materials [4].

Some research for the use of BFRP rebars in civil engineering still exist $[5 ; 6]$. Urbanski et al. showed that BFRP rebars are an "excellent alternative [...] as reinforcement due to minimizing the weight of the slab, having excellent resistance to corrosion effects and reducing repairs" $[7 ; 8]$.

Studies showed, that deflections of BFRP reinforced concrete beams are significantly higher than deflections of SRC beams [7]. These properties are caused by lower Young's modulus of the basalt rebars [8; 9]. It is also shown that the bond length and the rebar diameter can influence the mechanical behaviour of BFRP samples [8; 10].

\section{BASALT FIBRE REINFORCED MORTAR AND CONCRETE}

\subsection{Aim of investigation}

As one step to reach the aim of a retrofitting material, basalt fibre reinforced mortar and concrete were tested at the University of Applied Sciences Munich. Thin layers of retrofitting mortar have to resist high tension stresses. The aim of this test series was to determine, how much

* Corresponding author: benjamin.wolf@hm.edu 
fibres have to be added to a mortar mixture to improve the tension strength and the 3 point bending test results.

\subsection{Basalt fibre reinforced mortar mixture}

Basalt fibres were tested to add with different fibres contents within the mortar. As basalt fibre was used a product of the Deutsche Basalt Faser GmbH with bulk density of about $2,7 \mathrm{~g} / \mathrm{cm}^{3}$ and a tensile strength of 3000 - $4000 \mathrm{MPa}$. The used chopped basalt fibres have $24 \mathrm{~mm}$ length and an average diameter of about $0.4 \mathrm{~mm}$. The Young's Modulus of the fibre is 90 to $1000 \mathrm{GPa}$. A positive influence of basalt fibres on element's load capacity in relation to reference sample could be expected [11].

Table 1: Mortar mixture with different amounts of basalt fibre reinforcement

\begin{tabular}{|c|c|c|c|c|}
\hline$\left[\mathrm{kg} / \mathrm{m}^{3}\right]$ & $\mathrm{B} 0 \mathrm{a}$ & $\mathrm{B} 0,25$ & $\mathrm{~B} 2,0 \mathrm{w}$ & $\begin{array}{c}\mathrm{B} 0,3 \mathrm{FM} \\
04\end{array}$ \\
\hline $\begin{array}{c}\mathrm{CEM} \text { I } \\
\begin{array}{c}\mathrm{C} 2,5 \mathrm{~N} \\
{\left[\mathrm{~kg} / \mathrm{m}^{3}\right]}\end{array}\end{array}$ & 360 & 360 & 628 & 404 \\
\hline $\begin{array}{c}\text { Water } \\
{\left[\mathrm{kg} / \mathrm{m}^{3}\right]}\end{array}$ & 208 & 208 & 330 & 212 \\
\hline $\begin{array}{c}\text { Air void } \\
\text { content } \\
{[\text { Vol.-\%] }}\end{array}$ & 1.5 & 1.5 & 1.5 & 1.5 \\
\hline $\begin{array}{c}\text { Basalt } \\
\text { fibre } \\
\text { content }\end{array}$ & 0 & 0.25 & 2.00 & 0.30 \\
\hline $\begin{array}{c}\text { Aggregate } \\
0 / 4\left[\mathrm{~kg} / \mathrm{m}^{3}\right]\end{array}$ & 1784 & 1778 & 1166 & 1726 \\
\hline $\begin{array}{c}\text { Plastizicer } \\
{[\text { Vol-\% of }} \\
\text { cement] }\end{array}$ & - & - & - & 0.4 \\
\hline \begin{tabular}{c} 
w/c ratio \\
\hline
\end{tabular} & 0.58 & 0.58 & 0.53 & 0.53 \\
\hline
\end{tabular}

Table 1 shows - as an example- a few of the different mortar mixtures with different amounts of basalt fibres. Mixture B0a and also B0b are reference mixtures without fibres but different $\mathrm{w} / \mathrm{c}$ ratio. The mixture B0,25 is designed with the same component contents as B0 mixture, i.e. with identical w/c ratio, except the 0.25 Vol.- $\%$ basalt fibre content. In mixture B2,0w the cement paste content was enhanced due to poor workability of the fresh mortar. In mixture B03FM04 plasticizer was added; 0.4 M.- $\%$ of the cement content has been used.

\subsection{Properties of fresh basalt fibre reinforced concrete}

The workability of the basalt fibre reinforced mortar mixtures with different fibre content was determining the flow spread between 11 and $37 \mathrm{~cm}$, depending on the fibre content. For the mortar tests with the basalt fibre reinforced prisms $(160 \mathrm{~mm} \times 40 \mathrm{~mm}$ x $40 \mathrm{~mm})$ were produced. In Figure 1 the results of workability tests on the fresh mortar are shown in comparison to the results of the 3-point bending test on the prisms of hardened basalt fibre reinforced mortar. On the right hand side, the mixtures with plasticizer (signed with "FM") are presented. As expected they show higher values in the workability. Also the mixture B2,0w was more fluent than the others due to the enhanced water content and also the enhanced cement paste content. It can be determined that increasing the fibre content results in a significant worsening of the mortar workability, which already has been determined in other studies [3].

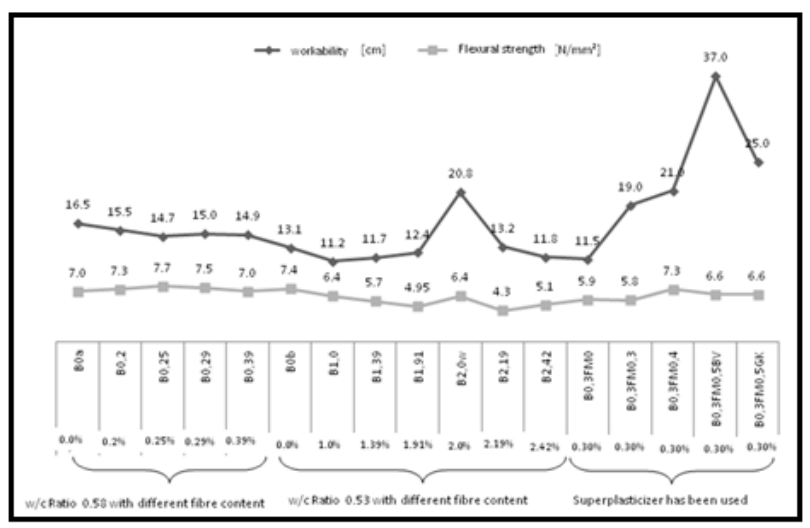

Figure 1: Workability (slump test) and 3-point-bending tensile strength of basalt fibre reinforced mortar prisms

\subsection{Mechanical properties of hardened basalt fibre reinforced concrete}

The test results of tensile strength are shown in Figure 3. The tested mixtures were all without plasticizer. The test specimens were notched with $5 \mathrm{~mm}$ depth in the middle part on two opposite sides of the prism, so a defined breaking surface was assured. On the upper und the lower end of the prism special prepared test equipment was fixed, which guaranteed an absolute axial tension strength test. The highest values were achieved with mixtures with basalt fibre content of 0.29 Vol.- $\%$ and a water cement ratio of 0.58 with $2.5 \mathrm{MPa}$. The crack opening in the failure zone at the moment of highest load is marked in Figure 3 with $\mathrm{dl}$ and showed also the highest value. The $\mathrm{dl}$ is defined as the crosshead travel which includes the self-deformation of glue. Fmax and $\mathrm{dl}$ are shown as the mean out of three measurements each.

In Figure 1 the results of the 3-point bending tests of the prisms with different amount of basalt fibre reinforcement are shown together with the workability results.

The highest values of 3-point bending tests match partially with higher values of workability tests. But not in every case, so a direct correlation cannot be assumed between these two parameters.

The investigation of the basalt fibre reinforced mortar prisms showed highest values in 3-point bending tests, tensile strength and also compressive strength with 0.3 Vol. \% basalt fibres in mixture. 


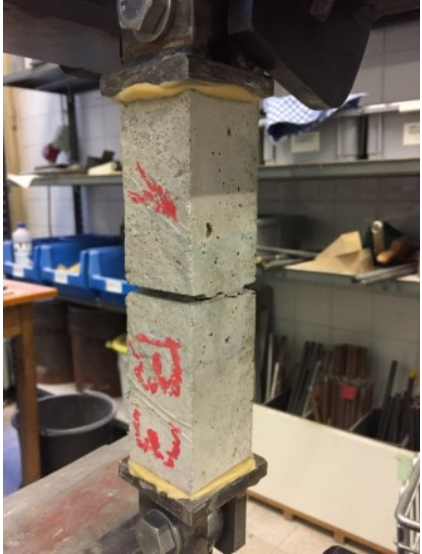

Figure 2: test setup for centric tension test

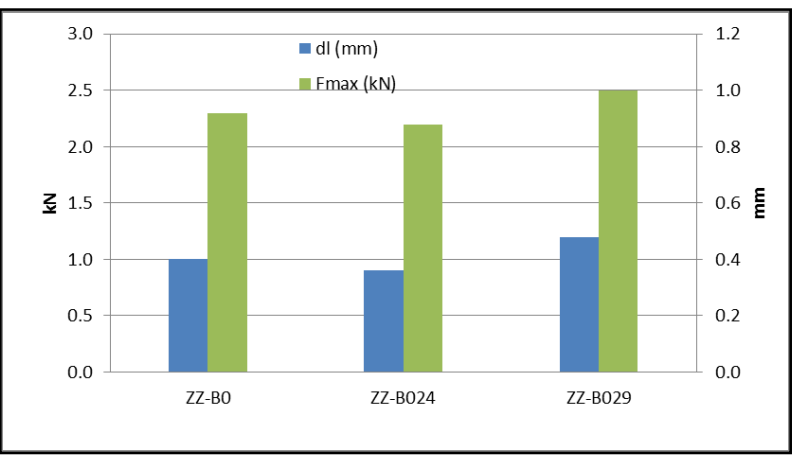

Figure 3: Axial tensile strength of notched basalt fibre reinforced mortar

Shrinkage tests showed negligible differences with different content of basalt fibres in mixture. But with shrinkage deformation in the range of $0.25 \mathrm{~mm} / \mathrm{m}$ the shrinkage is reduced compared to the shrinkage of ordinary concrete, which ease the application of basalt fibre reinforced mortar as thin retrofitting layer. The workability decrease with increasing fibre content which can easily be handled by an adapted content of superplasticizer: the optimum consistency can be achieved as can be seen in Figure 1.

\section{MECHANICAL PROPERTIES OF BASALT FIBRE REBARS}

\subsection{Experimental Setup}

Before testing the bonding properties of BFRP concrete samples mechanical parameters of basalt rebar have to be determined.

Dynamical fatigue tests of basalt-made rebars with conventional experimental setups at the University of Applied Sciences Munich showed unsatisfactory results with fatigue strength in the range of less than $10 \%$ of the tensile strength. These low determined fatigue strengths resulted from indentations of the basalt rebars, depending on the strength of the epoxy-based layer as well as indentations of the clamping in the former test setup. For this reason several special experimental setups were designed to obtain representative test result.
The specimens (basalt fibre rebars with diameter of $10 \mathrm{~mm}$ and length of $1000 \mathrm{~mm}$ ) were placed in a clamping device with jaws made of polyamide. The torque value can be set in a way that there is no indentation damage at the rebar but ensures the necessary bond strength within the clamping under testing load. Three rebars with grain-covered rebar surfaces were investigated. As Lin and Zhang showed, these types of samples perform best among all other types of rebar surfaces [12].

To prevent measurement uncertainties like slip in the clamping or material deformation of the polyamide jaws, a fine strain extensometer has been mounted to determine the Young's Modulus, as can be seen in Figure 4 . On the left side the detailed test setup can be seen. The measurement of Young's modulus takes place in the centre of the rupture area.

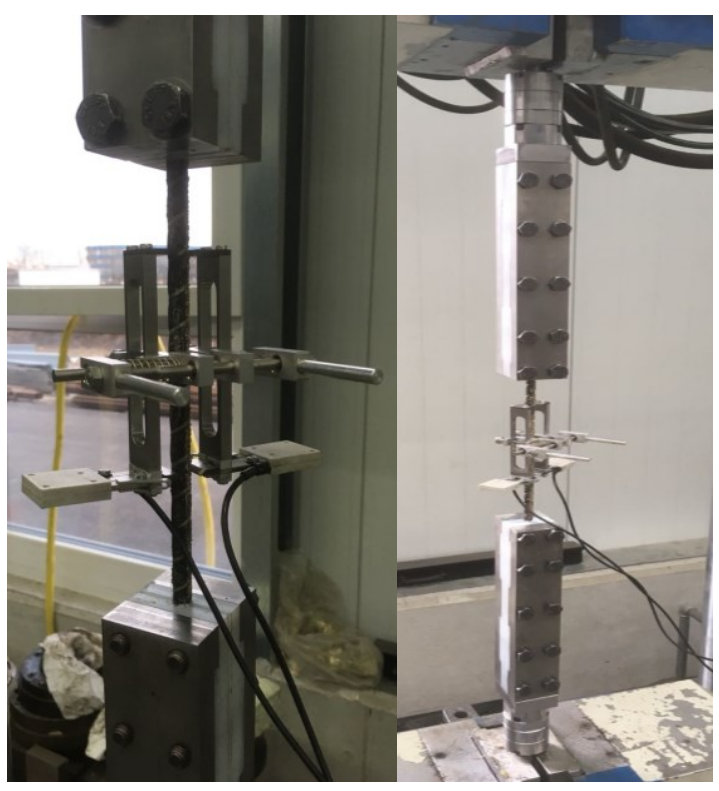

Figure 4: Test setup for statical tensile test of basalt rebar with mounted fine strain extensometer

\subsection{Results of Tensile Strength and Young's modulus of Basalt Rebars}

Figure 5 shows a force-deformation-diagram of steel and basalt rebar in batches of four samples each. Basalt rebars obtain higher tensile strength values than B500S steel reinforcement samples. As expected abrupt failure occurs for the basalt rebars. The results of basalt rebar show ultimate loads in range of 60 to $80 \mathrm{kN}$, which is expected to be sufficient for strengthening facades.

Next step was to determine the Young's-Modulus of the basalt reinforcement bars. Table 2 shows the Young's-modulus values of ten basalt reinforcement samples as well as the maximum strength of each sample. The mean value of the Young's-Modulus obtained from these samples is determined to $52^{\prime} 065 \mathrm{~N} / \mathrm{mm}^{2}$. However it should be noted that the intrinsic value of the bar diameter is about $8.91 \mathrm{~mm}$ (manually determined by averaging ten measurement points). Taking into account the assumed bar diameter of 
$10 \mathrm{~mm}$, the Young's-Modulus average value is about $41^{\prime} 000 \mathrm{~N} / \mathrm{mm}^{2}$. This calculated value is in the range of glass fibre reinforcement bars [12]. Remarkably all testing samples fail in locations within the testing area, which indicates an accurate force transmission of the developed test device.

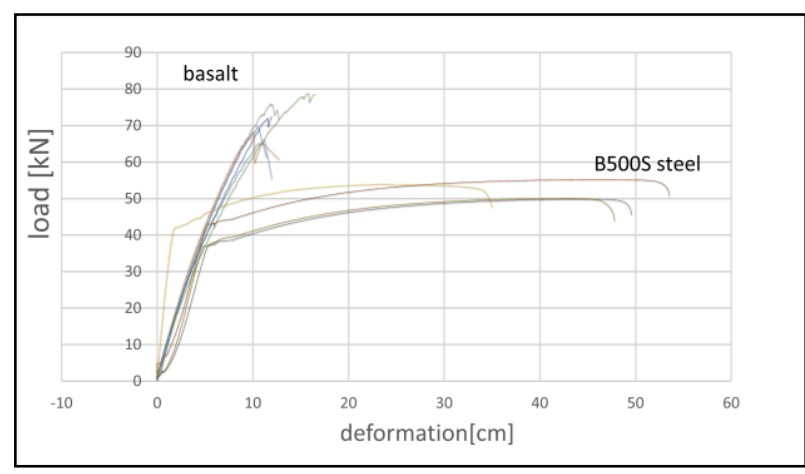

Figure 5: force-deformation-diagram of steel and basalt rebars

Table 2: Evaluation of basalt rebar properties, calculated with diameter of $8.91 \mathrm{~cm}$

\begin{tabular}{|c|c|c|c|}
\hline & $\begin{array}{l}\text { Young's- } \\
\text { Modulus } \\
{\left[\mathrm{N} / \mathrm{mm}^{2}\right]}\end{array}$ & $\begin{array}{l}F_{\max } \\
{[\mathrm{kN}]}\end{array}$ & $\begin{array}{c}\text { Tensile } \\
\text { strength } \\
{\left[\mathrm{N} / \mathrm{mm}^{2}\right]}\end{array}$ \\
\hline 1 & $51^{\prime} 799$ & 64.93 & \\
\hline 2 & $51 ' 634$ & 73.15 & \\
\hline 3 & $53^{\prime} 624$ & 65.15 & \\
\hline 4 & $52 ' 623$ & 77.95 & \\
\hline 5 & $51^{\prime} 898$ & 69.25 & \\
\hline 6 & $51^{\prime} 799$ & 72.94 & \\
\hline 7 & $50 ’ 634$ & 67.45 & \\
\hline 8 & $52 ’ 151$ & 77.65 & \\
\hline 9 & $52^{\prime} 643$ & 72.52 & \\
\hline 10 & $51^{\prime} 861$ & 78.78 & \\
\hline Mean value & $52 ’ 065$ & 71.75 & 1152 \\
\hline
\end{tabular}

\section{INVESTIGATIONS ON BFRP CONCRETE SAMPLES}

\subsection{Material}

Various testing procedures were conducted to study the behaviour of BFRP in concrete matrix. All data obtained are evaluated in reference to B500S steel reinforcement specimens. Table 33 shows the concrete mixture which has been used for all specimens of the described investigation.

Table 3: Concrete mixture of concrete samples

\begin{tabular}{|c|c|}
\hline component & \\
\hline $\begin{array}{c}\text { CEM I 42,5 N } \\
{\left[\mathrm{kg} / \mathrm{m}^{3}\right]}\end{array}$ & 354 \\
\hline $\begin{array}{c}\text { Water } \\
{\left[\mathrm{kg} / \mathrm{m}^{3}\right]}\end{array}$ & 191 \\
\hline $\begin{array}{c}\text { Plasticizer } \\
{[\text { Vol-\% of }} \\
\text { Cem. }]\end{array}$ & 0.4 \\
\hline $\begin{array}{c}\text { Aggregate 0/4 } \\
{\left[\mathrm{kg} / \mathrm{m}^{3}\right]}\end{array}$ & 1239 \\
\hline $\begin{array}{c}\text { Aggregate } \\
\mathbf{4} / \mathbf{1 6} \\
{\left[\mathrm{kg} / \mathrm{m}^{3}\right]}\end{array}$ & $596-$ \\
\hline $\mathbf{w} / \mathbf{c ~ r a t i o}$ & 0.54 \\
\hline
\end{tabular}

\subsection{Experimental setup and testing program}

The test setup for 3-point bending test is shown in figure 6 . It can be seen that the test specimens are reinforced with three rebars. For detecting the vertical deflection an extensometer has been used. The steel angle, on which the extensometer has been mounted, was fixed with two anchors. Every specimen has been preloaded with $200 \mathrm{~N}$. At this point the values of the extensometer have been zeroed. After that test load has been increased continuously until failure.

Figure 7 shows testing setup for central tension test program. It can be seen that the test specimens were reinforced with two rebars. To ensure practical geometry of the testing samples the maximum grain size has been reduced to $8 \mathrm{~mm}$.

As the basalt reinforcement bars are vulnerable for lateral pressure the specimens have to be glued to the test setup. It can be seen that there are two extensometers in the test setup. The impact length was determined to be $45 \mathrm{~cm}$.

Every specimen has been loaded with $40 \mathrm{kN}$. Then the test program has been stopped and the crack widths have been measured. In the subsequent analysis the sum of the crack widths have been compared with the results of the extensometers which were positioned at the longitudinal sides of the specimens. 


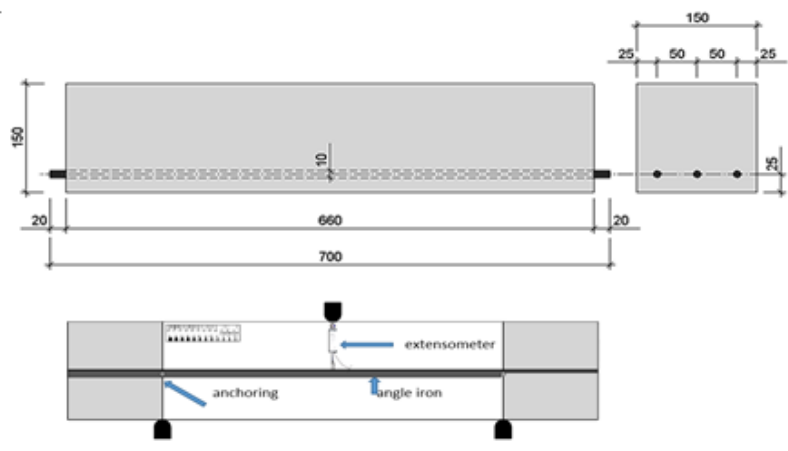

Figure 6: Test setup for 3-point-bending test

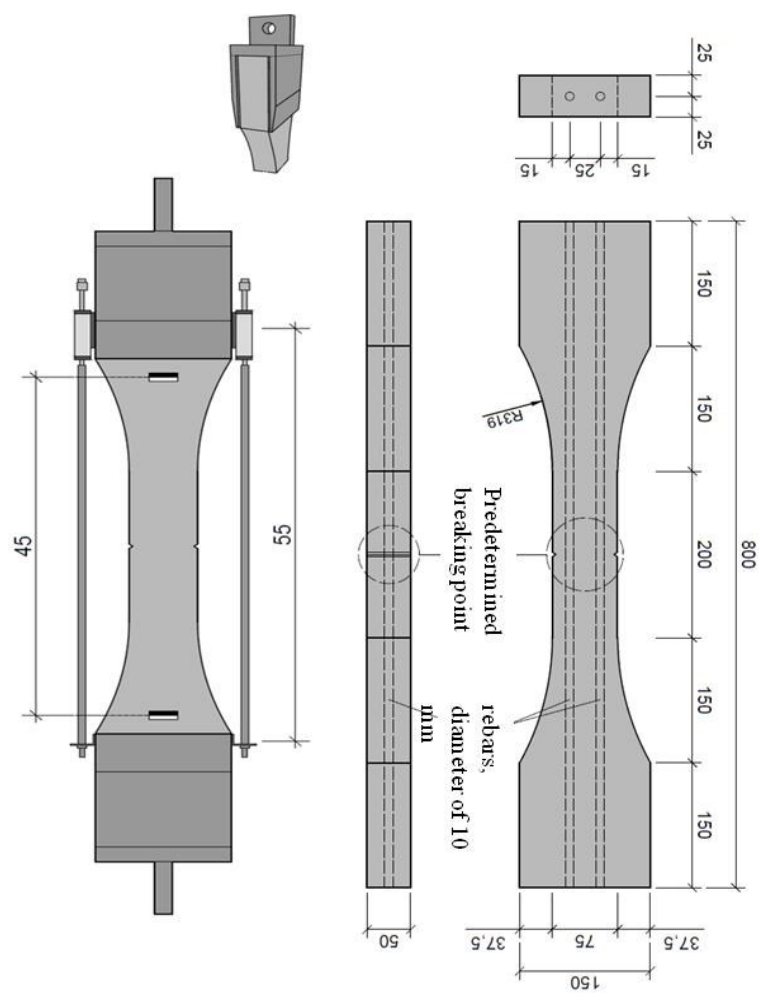

Figure 7 : Test setup for centric tension test

\subsection{Flexural strength of BFRP reinforced concrete}

Table 4 and Table 5show the comparison between SRC and BFRP concrete specimens by using 3-point-bending test. BFRP concrete specimens show considerably higher vertical deflection results than SRC specimens. Furthermore BRFP specimens can take higher breaking loads than SRC specimens.

Figure 8 , which is turned $90^{\circ}$, shows examples of the crack pattern of BRFC and SRC specimens tested in 3point-bending. Some distinct differences can be seen. Mean values of crack widths measured after completed crack formation can be seen in Table 6 . It can be seen that BFRP concrete beams score higher crack widths than SCR samples. Related cracking loads can be seen in Table 7.
Table 4: Comparison of vertical deflection of SRC and BFRP when achieving the failure load

vertical deflection $[\mathrm{mm}]$

\begin{tabular}{|l|l|l|l|l|l|l|}
\hline & \multicolumn{3}{|l|}{ SRC B500S } & \multicolumn{3}{l|}{ BFRC } \\
\hline Sample & V1-01 & V1-02 & V1-03 & V1-01 & V1-02 & V1-02 \\
\hline 3-p-b & 2.50 & 2.50 & 2.45 & 6.04 & 6.60 & $7 ., 3$ \\
\hline
\end{tabular}

Table 5: Comparison of failure load values of SRC and BFRP -Specimens

\begin{tabular}{|c|c|c|c|c|c|c|}
\hline \multicolumn{5}{|l|}{ Failure load values [kN] } & \multicolumn{3}{l|}{ BFRC } \\
\hline & \multicolumn{2}{l|}{ SRC B500S } & \\
\hline Sample & V1-01 & V1-02 & V1-03 & V1-01 & V1-02 & V1-03 \\
\hline 3-p-b & 98.16 & $120, .17$ & 98.24 & 134.40 & 153.39 & 143.25 \\
& & & & & & \\
\hline
\end{tabular}

In the fracture surface of BRFP concrete bar specimen lots of secondary cracks in the axis of reinforcement rebar can be seen. This indicates that failure in the bonding area between rebar and concrete matrix has taken place. This hypothesis is supported particularly in regard to the primary crack of the BRFP concrete specimen (can be seen in Figure 8 in the area between 50 and $55 \mathrm{~cm}$ of scale). The cracks outside the constant-moment region can be affected by a combination of flexural and shear stresses [9].

When the load is increased in the 3-point-bending test to failure using BFRP concrete specimens, it can be assumed that there is bonding failure of the specimens reinforced with basalt reinforcement bars. There is loss of adhesion in the cracking area, which can be seen in Figure 8 and Figure 9, while basalt reinforcement bars did not suffer any damage. When debonding occurs, slip takes place between the reinforcement bars and surrounding concrete [12].

The load carrying capacity of the SRC specimens was preserved even with high deflection. Thus not all of the samples could be deformed until failure of the specimens in the current test setup.

Table 6: crack widths 3-point bending test before achieving the failure load

\begin{tabular}{|ll|ll|}
\hline SRC & & BFRP & \\
\hline 3.B-St-V1-01 & $0.32 \mathrm{~mm}$ & 3.B-Ba-V1-01 & $0.71 \mathrm{~mm}$ \\
3.B-St-V1-02 & $0.37 \mathrm{~mm}$ & 3.B-Ba-V1-02 & $0.52 \mathrm{~mm}$ \\
3.B-St-V1-03 & $0.29 \mathrm{~mm}$ & 3.B-Ba-V1-03 & $0.66 \mathrm{~mm}$ \\
& & & \\
3.B-St-V2-01 & $0.18 \mathrm{~mm}$ & 3.B-Ba-V2-01 & $0.38 \mathrm{~mm}$ \\
3.B-St-V2-02 & $0.25 \mathrm{~mm}$ & 3.B-Ba-V2-02 & $0.39 \mathrm{~mm}$ \\
3.B-St-V2-03 & $0.30 \mathrm{~mm}$ & 3.B-Ba-V2-03 & $0.65 \mathrm{~mm}$ \\
\hline
\end{tabular}




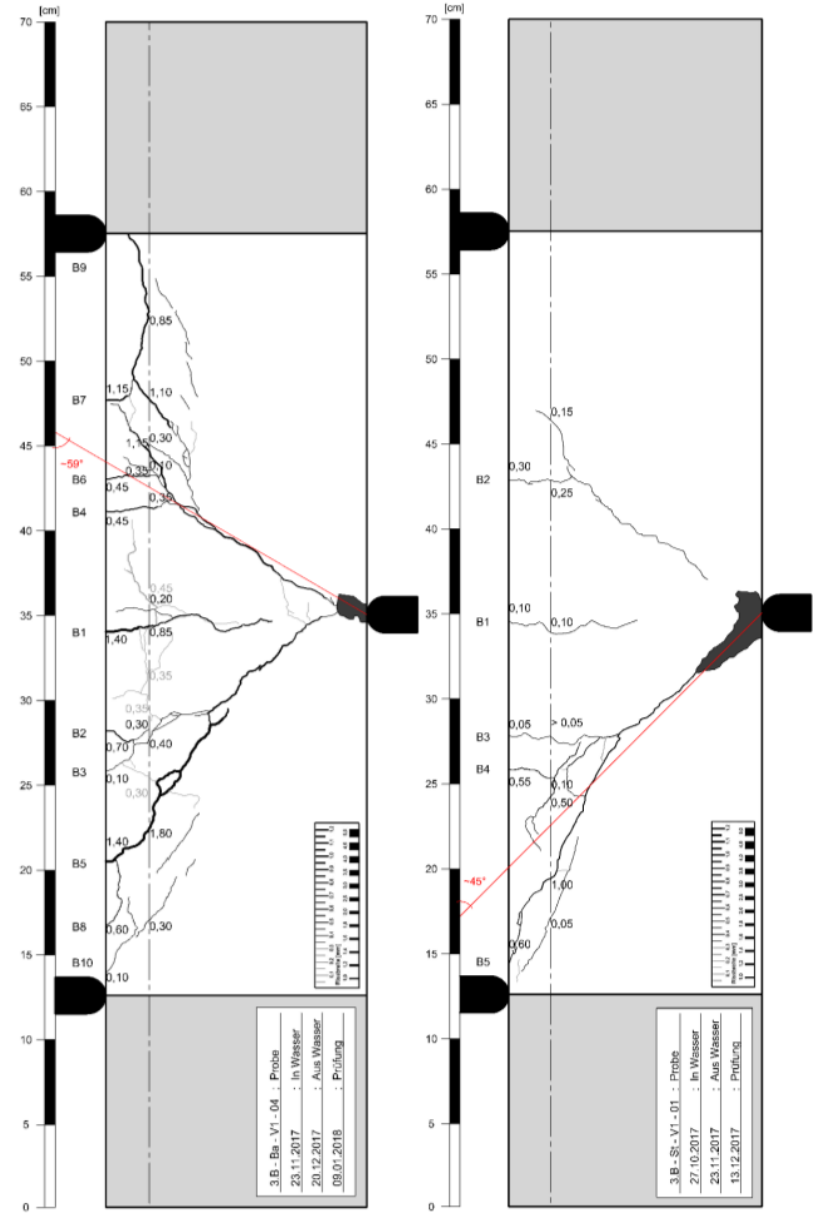

Figure 8 Comparison of cracking pattern between BFRP concrete (left) and SRC concrete samples (right)

Table 7: Example of developing of bending cracks by load

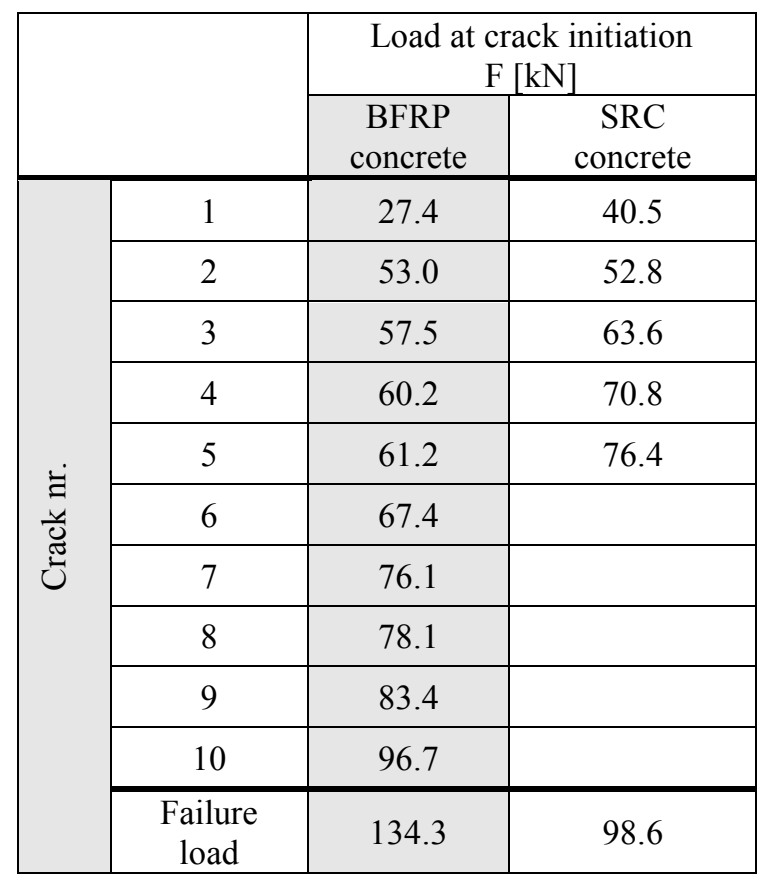
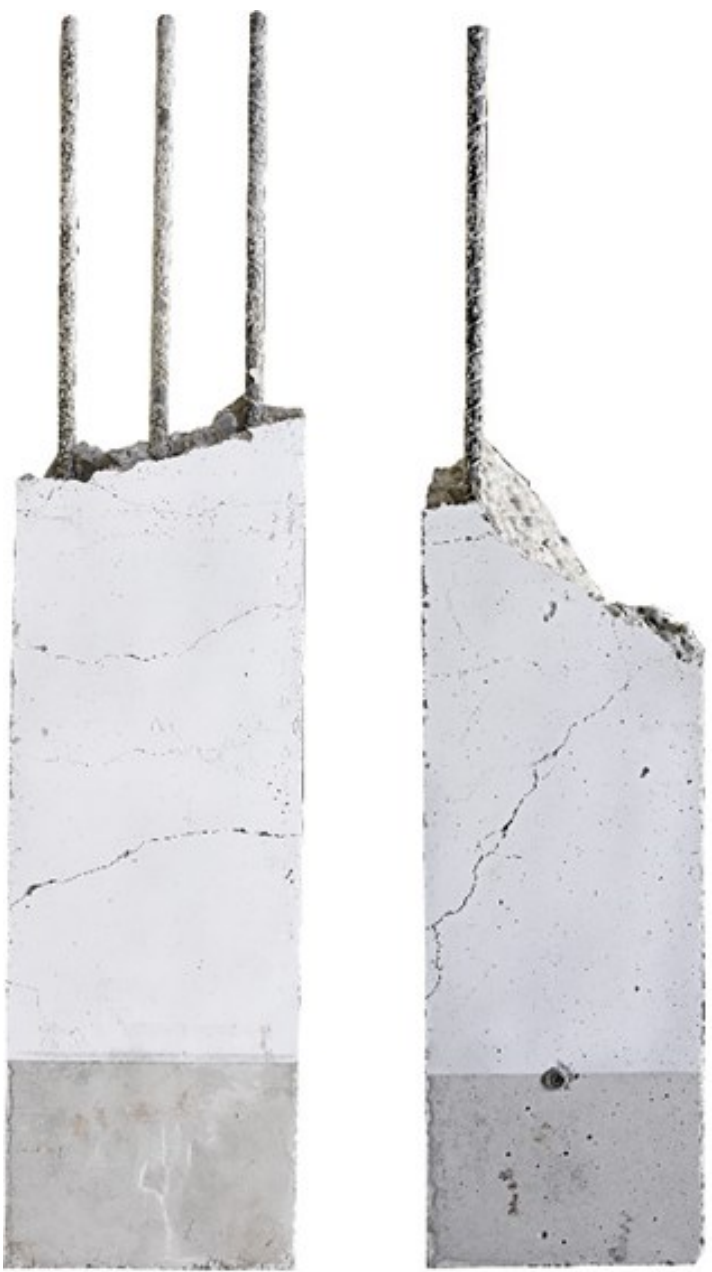

Figure 9: BFRC specimen crack pattern after bonding failure

\subsection{Central tension test}

Figure 10 and Figure 11 show central tension test results of BFRC specimens and SRC specimens. BFRC bones show larger deformations than SRC specimens. Using the graphic charts it is possible to retrace the crack initiation scheme of the specimens. It can be seen that there are larger crack widths at the damage pattern of BFRC specimens than SRC. There are already first indications that adhesion of concrete matrix and basalt reinforcement has exceeded and slip has been occurred (Figure 12): BFRP concrete specimens show longitudinal cracks on the sides, marked with the symbols "R" and "L". Furthermore there can be viewed secondary cracks in the test surfaces of the BFRP concrete samples. This could be another sign for bonding failure.

On the other the damage patterns of SRC specimen show cracks at regular intervals (seen at Figure 13). Furthermore no secondary cracking can be seen in the surfaces of SRC samples. Thus there is no indication that there is bonding failure between steel reinforcement and cement matrix.

In contrast to the damage pattern there is no big difference in the strength of crack initiation, which can be seen in Table 8 . This table shows the cracking loads for the primary cracks 1-8. First Primary cracks are 
created in range of 7.6 to $11.9 \mathrm{kN}$ in all test samples. Crack no. 8 is induced at a force of 21.6 to $23.8 \mathrm{kN}$.

Due to the lower Young's modulus of the basalt reinforcement bars (approx. 52'000 N/mm² compared to $210^{\prime} 000 \mathrm{~N} / \mathrm{mm}^{2}$ of steel) the BFRP samples (Figure 11) show larger deformations than SCR samples (Figure 10). The crack pattern given in Figure 12 confirms that the sum of the crack widths of BFRP samples is consistent with the values of the extensometers (Figure 11).

Table 8 : Load of crack initiation

\begin{tabular}{|c|c|c|c|c|c|c|c|}
\hline & \multicolumn{6}{|c|}{ Load of crack initiation $\mathrm{F}[\mathrm{kN}]$} \\
\hline & & \multicolumn{3}{|c|}{$\begin{array}{l}\text { Basalt (BFRC), } \\
2 \times \varnothing 10 \mathrm{~mm}\end{array}$} & \multicolumn{3}{|c|}{$\begin{array}{c}\text { SRC, } \\
2 \times \varnothing 10 \mathrm{~mm}\end{array}$} \\
\hline \multirow{9}{*}{ 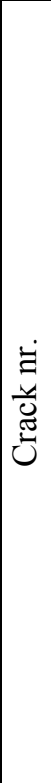 } & & $\begin{array}{l}\text { V2- } \\
\text { B-01 }\end{array}$ & $\begin{array}{l}\text { V2- } \\
\text { B-02 }\end{array}$ & $\begin{array}{l}\text { V2- } \\
\text { B-03 }\end{array}$ & $\begin{array}{l}\text { V2- } \\
\text { S-01 }\end{array}$ & $\begin{array}{l}\text { V2- } \\
\text { S-02 }\end{array}$ & $\begin{array}{l}\text { V2- } \\
\text { S-03 }\end{array}$ \\
\hline & 1 & 9.5 & 11.9 & 8.1 & 12.3 & 10.4 & 7.6 \\
\hline & 2 & 10.1 & 14.8 & 10.8 & 12.9 & 11.1 & 10.3 \\
\hline & 3 & 12.4 & 17.2 & 12.0 & 14.6 & 12.6 & 15.2 \\
\hline & 4 & 13.4 & 21.3 & 12.4 & 16.4 & 15.5 & 20.1 \\
\hline & 5 & 17.2 & 21.8 & 13.5 & 18.5 & 17.4 & 20.8 \\
\hline & 6 & 20.8 & 22.0 & 22.1 & 20.5 & 20.2 & 22.0 \\
\hline & 7 & 21.8 & 20.8 & 21.6 & 22.3 & 19.4 & 21.8 \\
\hline & 8 & 22.3 & 21.6 & 23.9 & 23.8 & 22.0 & 23.7 \\
\hline
\end{tabular}

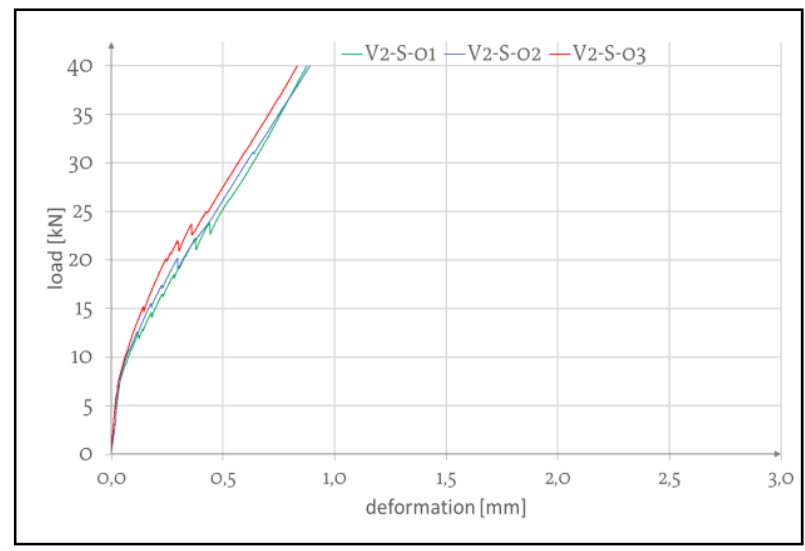

Figure 10: central tension test results of SRC specimen

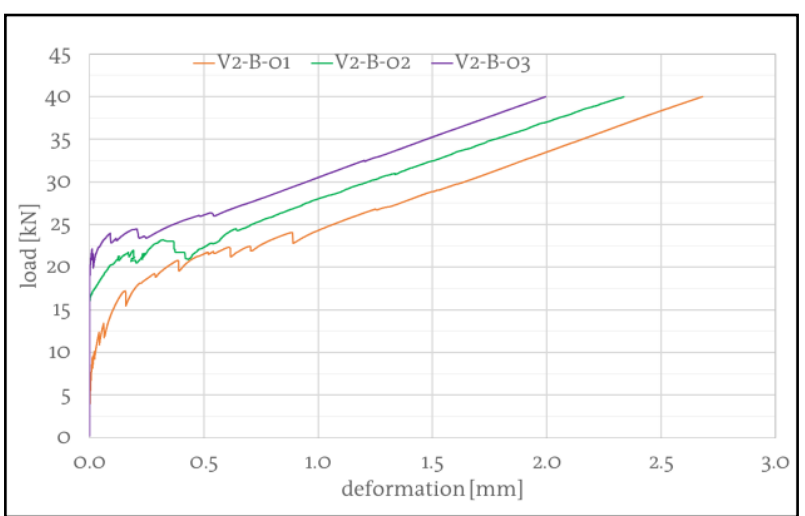

Figure 11: central tension test results of BFRP specimen

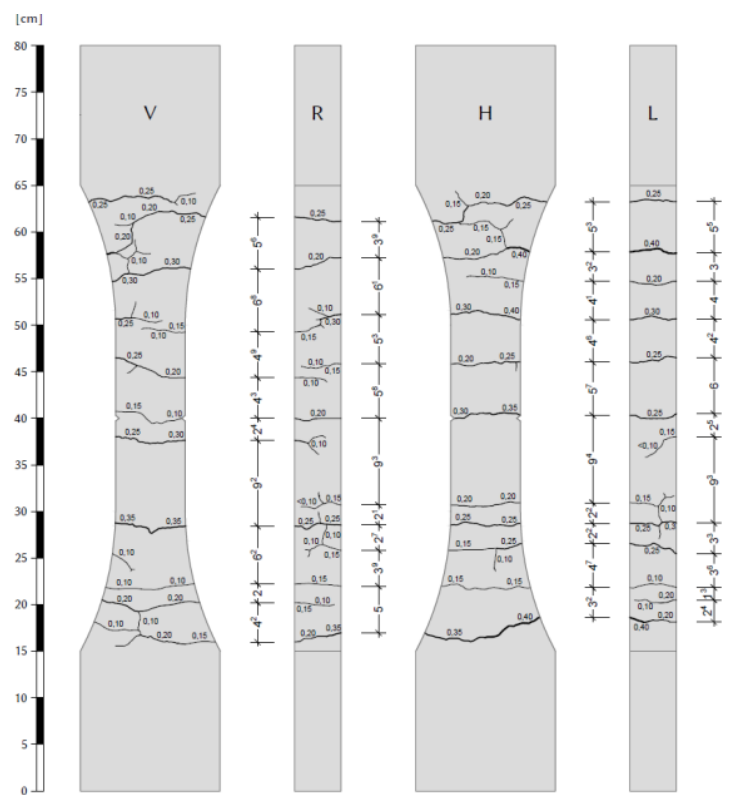

Figure 12 : crack pattern example of BFRP specimen V2-B02 after central tension test

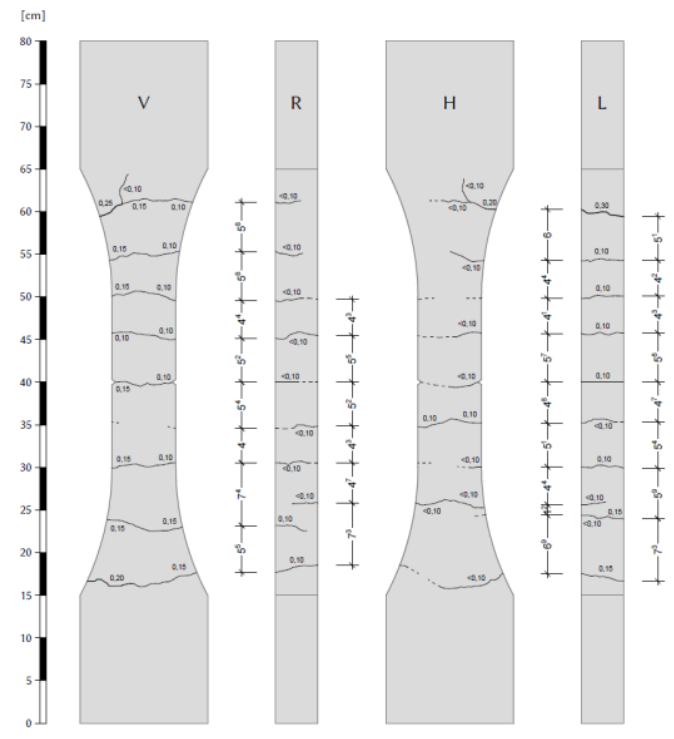

Figure 13: crack pattern example of SRC specimen V2S02 after central tension test 


\section{Conclusions}

In this paper, the effect of using chopped basalt fibres in mortar mixtures as well as the mechanical behaviour of BFRP concrete rebars and BFRP reinforced concrete beams were investigated.

Based on the experimental results and discussion the conclusions can be summarized as following:

- Tests with basalt fibre reinforced mortar with prisms showed highest values in 3-point-bending tests, tensile strength and also compressive strength with 0.3 Vol. \% basalt fibres in mixture.

- The specially developed test set-up ensures testing the mechanical behaviour without causing any damage of the basalt rebars.

- BFRP concrete samples can take higher breaking loads in 3-point-bending test compared to SRC samples. But, on the other hand, after failure in the bonding area has been occurred, no residual load capacity remains.

- Several indicators confirm that there is an exceeding of the adhesion of the BFRP in the bonding area of basalt reinforced bars and concrete matrixes leading to slipping of the BFRP in the matrix causing a failure without load capacity remaining.

- High tensile strength of BFRP concrete beams (in comparison to SRC samples) show that the material is well suited for use as retrofitting facade elements. It has be considered that BRFP reinforced concrete has higher vertical deflection values with same load levels.

- Some studies modelling the deformation behaviour have to be carried out to confirm the laboratory results described in this paper.

- The failure behaviour of the bonding zone will be the subject of further studies.

- Fatigue performance of BFRP concrete beams are currently carried out.

\section{References}

[1] Van de Velde, K., Kiekens, P., Langenhove, L.: Basalt fibers as reinforcement for composites. International Composites News (2002).

[2] Rybin, V. A., Utkin, A.V., Baklanova, N. I.: Corrosion of uncoated and oxide-coated basalt fibre in different alkaline media. Corrosion Science 102 (2016), S. 503-509.

[3] Zielinski, K., Olszewski, P.: Der Einfluss von Basaltfasern auf ausgewählte physische und mechanische Eigenschaften von Zementmörtel. (The impact of basaltic fibre on selected physical and mechanical properties of cement mortar). BFT International (2005).

[4] Ralegaonkar, R.; Gavali, H.; et al.: Application of chopped basalt fibers in reinforced mortar. A review. Construction and Building Materials 164 (2018), S. 589-602.
[5] Wang, H., Sun, X., Peng, G., Luo, Y., Ying, Q.: Experimental study on bond behaviour between BFRP bar and engineered cementitious composite. Construction and Building Materials 95 (2015), S. 448-456.

[6] Branston, J., Das, S., Kenno, S. Y., Taylor, C.: Mechanical behaviour of basalt fibre reinforced concrete. Construction and Building Materials 124 (2016), S. 878-886.

[7] Lapko, A., Urbański, M.: Experimental and theoretical analysis of deflections of concrete beams reinforced with basalt rebar. Archives of Civil and Mechanical Engineering 15 (2015), S. 223-230.

[8] Urbanski, M., Lapko, A., Garbacz, A.: Investigation on Concrete Beams Reinforced with Basalt Rebars as an Effective Alternative of Conventional R/C Structures. Procedia Engineering 57 (2013), S. 1183 1191.

[9] Elgabbas, F., Vincent, P., Ahmed, E. A., Benmokrane, B.: Experimental testing of basalt-fiberreinforced polymer bars in concrete beams. Composites Part B: Engineering 91 (2016), S. 205218.

[10] Yeboah, D., Taylor, S., McPolin, D., Gilfillan, R.: Pull-out behaviour of axially loaded Basalt Fibre Reinforced Polymer (BFRP) rods bonded perpendicular to the grain of glulam elements. Construction and Building Materials 38 (2013), S. 962-969.

[11] Wlodarczyk, M., Jedrzejewski, I.: Concrete Slabs Strengthened with Basalt Fibres - Experimental Tests Results. Procedia Engineering 153 (2016), S. 866-873.

[12] Lin, X., Zhang, Y. X.: Bond-slip behaviour of FRPreinforced concrete beams. Construction and Building Materials 44 (2013), S. 110-117. 